\title{
Cellular pathogenesis in prion diseases
}

\author{
Carole CROzET, Florence BeRANGER, Sylvain LEHMANN*
}

Institut de Génétique Humaine, CNRS-UPR1142, 141 rue de la Cardonille, 34396 Montpellier Cedex 5, France

(Received 21 September 2007; accepted 15 April 2008)

\begin{abstract}
Prion diseases are characterised by neuronal loss, vacuolation (spongiosis), reactive astrocytosis, microgliosis and in most cases by the accumulation in the central nervous system of the abnormal prion protein, named $\mathrm{PrP}^{\mathrm{Sc}}$. In this review on the "cellular pathogenesis in prion diseases", we have chosen to highlight the main mechanisms underlying the impact of $\mathrm{PrP}^{\mathrm{C}} / \mathrm{PrP}^{\mathrm{Sc}}$ on neurons: the neuronal dysfunction, the neuronal cell death and its relation with $\mathrm{PrP}^{\mathrm{Sc}}$ accumulation, as well as the role of $\mathrm{PrP}^{\mathrm{Sc}}$ in the microglial and astrocytic reaction.
\end{abstract}

Prion / neurodegeneration / cell death / neuronal dysfunction / gliosis

Table of contents

1. Introduction .1

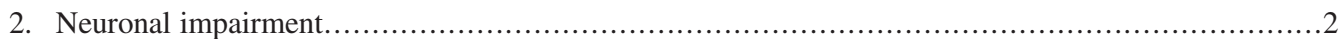

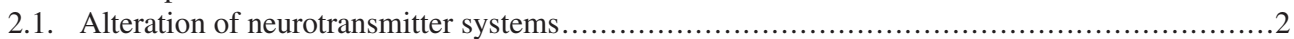

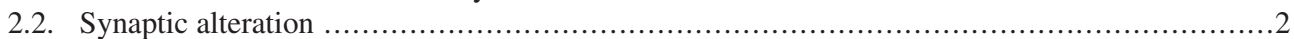

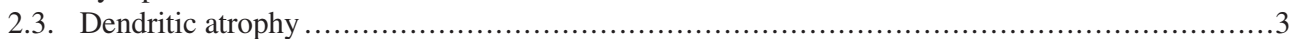

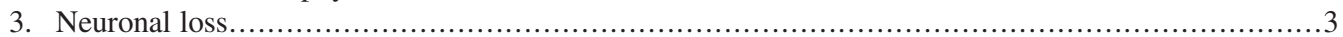

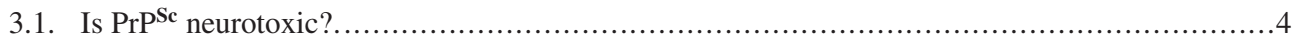

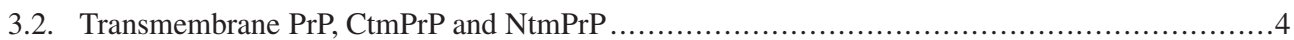

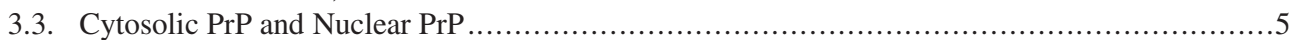

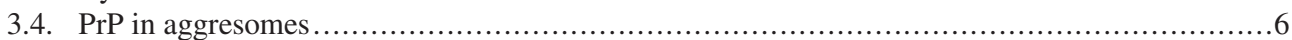

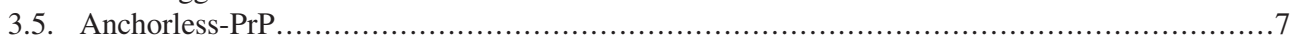

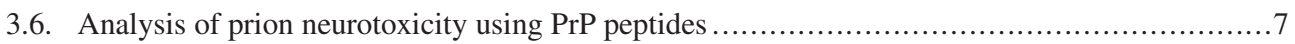

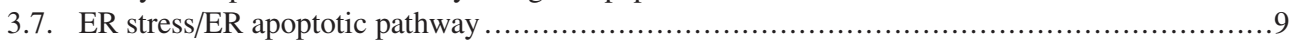

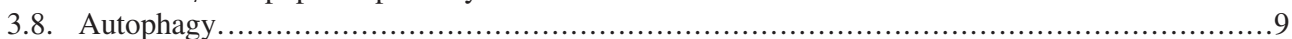

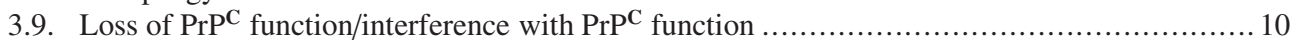

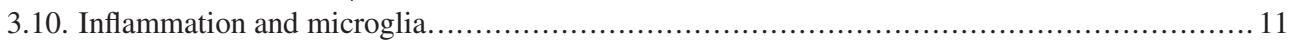

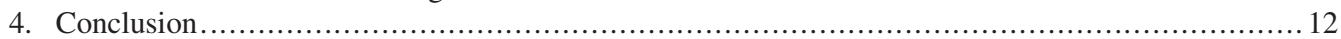

\section{INTRODUCTION}

Prion diseases are characterised by neuronal loss, vacuolation (spongiosis), reactive astrocytosis, and microgliosis. They are associated in most cases with the accumulation in the central nervous system (CNS) of the abnormal protease resistant prion protein, named

* Corresponding author:

sylvain.lehmann@igh.cnrs.fr
$\mathrm{PrP}^{\mathrm{Sc}}$ resulting from the post-translational conversion of the normal host-encoded $\mathrm{PrP}^{\mathrm{C}}$ protein $[96,97]$. These few general sentences that often, if not always, start reviews and prion articles are particularly relevant in the context of this review that sets out to address the vast issue of 'cellular pathogenesis in prion diseases'. They also prompt us to focus on the impact of disease associated PrP species production/accumulation on neurons 
(neuronal dysfunction, neuronal cell death) and on astocytes and microglia.

\section{NEURONAL IMPAIRMENT}

Although severe cognitive deficits observed in transmissible spongiform encephalopathies (TSE) may result from neuronal loss, early behavioural impairments are probably related to primary neuronal dysfunction. This has been exemplified in a recent study by Mallucci et al. $[73,74]$ who have shown that behavioural and synaptic impairments, as well as spongiosis, recover when neuronal $\operatorname{PrP}^{C}$ is depleted. These results suggest that early functional impairments precede neuronal loss in prion disease. Moreover, this rescue occurred before extensive $\mathrm{PrP}^{\mathrm{Sc}}$ deposition, supporting the concept that a PrP transient species, distinct from aggregated $\mathrm{PrP}^{\mathrm{Sc}}$ may be involved. Little is known about the cellular mechanisms underlying prion disease neuronal dysfunctions. Cellular models are poorly representative of the complexity of neuronal circuitry and their susceptibility to prion strains is limited [122]. Therefore, neuropathological data of the different prion strains, which are able to induce different but specific lesions in the infected brain $[13,36]$, result mainly from histopathological or biochemical examination of human brain or animal models.

\subsection{Alteration of neurotransmitter systems}

Several neurotransmitter systems (acetylcholine, GABA (Gamma-aminobutyric acid), dopamine, etc.) are damaged in TSE. Loss of GABAergic neurons appeared to be the first detectable neuropathological change. Presynaptic bouton loss (and alteration with presence of abnormally aggregate vesicles) is also observed, but only at the terminal stages of disease. This is associated with a significant decrease of the stimulated $[3 \mathrm{H}]-\mathrm{GABA}$ release from synaptosomes and with the accumulation of $\mathrm{PrP}^{\mathrm{Sc}}$. Functional abnormalities could thus be linked to $\mathrm{PrP}^{\mathrm{Sc}}$ deposition [7]. Alterations may be also attributed to $\operatorname{PrP}^{\mathrm{C}}$ loss of function since hippocampal slices from PrP null mice have weakened GABA receptor-mediated fast inhibition and impaired long-term potentiation [23]. This impaired synaptic inhibition could be involved in the epileptiform activity seen in Creutzfeldt-Jakob disease (CJD) [23]. Some studies performed during the late stages of TSE have also indicated altered concentrations of dopamine, norepinephrine and serotonin in scrapie-infected animal models [3, 48]. Additional studies have reported the results of behavioural tests and monoamine concentrations in hamsters at different times after infection with the scrapie $263 \mathrm{~K}$ strain. They have shown significant changes in spontaneous motor activity later after infection correlated with a marked alteration in serotoninergic function. Ten days before any evident clinical signs and motor disturbances, memory deficit related to alteration in the dopaminergic system (assessed by metabolite/dopamine ratios measures) was also found in the infected animals [2]. The serotonergic system has also been analysed in human TSE by measuring the size and number of tryptophan hydroxylase (TPH) positive cells in the dorsal raphe. While there were no differences in the number of TPH-positive cells, the mean TPH-positive cell size and TPH staining intensity was significantly greater in CJD compared to controls, suggesting a pathological over-activity of the brain serotonergic systems in CJD. This may result in excessive release of 5HT (5-hydroxytryptamine or serotonin) within the brain, leading to clinical symptoms such as fluctuating attention and arousal [44]. Other changes in neuropeptide expression in mice infected with prion have also been reported [31]. Neuropeptide Y (NPY), enkephalin and dynorphin-like immunoreactivities increased in mossy fibers of infected mice, whereas cholecystokinin-like immunoreactivity decreased compared to non infected mice [31]. These modifications in neuropeptides ratio may trigger abnormal response in the infected brain.

\subsection{Synaptic alteration}

In experimental scrapie, loss of synapses is also an early abnormality. In ME7 infected mice, there is a significant reduction in synaptophysin in the CA1, 13 weeks after ME7 hippocampic injection, indicating loss of presynaptic terminals [29]. In addition, in 
sporadic CJD brains, it has been reported a decreased expression of crucial proteins (synaptophysin, p38, synaptosomal-associated protein (SNAP-25), syntaxin-1, synapsin-1, $\alpha$ and $\beta$-synuclein and Rab3a). Moreover, synaptic protein accumulation in the soma and axonal torpedoes of Purkinje cells could result in the impairment of axonal transport $[41,114]$. Defects in axonal transport and synaptic dysfunctions have also been challenged by testing the effect of full-length mammalian prion protein rPrP fibrils on human embryonic teratocarcinoma NTERA2 cells (NT2) that were terminally differentiated into neuronal and glial cells and co-cultured. The authors have observed degeneration of neuronal processes accompanied by a collapse of microtubules and aggregation of cytoskeletal proteins, formation of neuritic beads, and a dramatic change in localization of synaptophysin [88]. Whether these changes are linked to abnormal $\operatorname{PrP}$ metabolism is not known. However, in retina and optic nerves, it has been shown that like its normal counterpart $\mathrm{PrP}^{\mathrm{C}}$, most $\mathrm{PrP}^{\mathrm{Sc}}$ remained associated with lipid rafts while usual PrPinteracting proteins caveolin-1 and synaptophysin shifted to non-detergent-resistant membrane (non-DRM) fractions during the course of scrapie infection. This suggests that the conversion of $\mathrm{PrP}^{\mathrm{C}}$ into $\mathrm{PrP}^{\mathrm{Sc}}$ could modify the $\mathrm{PrP}^{\mathrm{C}} /$ caveolin-1/synaptophysin complex [107].

\subsection{Dendritic atrophy}

Dendritic atrophy is also a prominent feature of prion diseases [63]. A recent report has shown that Notch activation (which is implicated in both dendrite growth and maturation) may be involved in this atrophy. Indeed, the released cleaved intracellular fragment of Notch-1 (NICD) increased concomitantly with $\mathrm{PrP}^{\mathrm{Sc}}$ levels in the neocortex of infected mice. In addition, increased levels of Notch-1 mRNA and translocation of NICD to the nucleus correlated well with regressive dendritic changes. Furthermore, compared to uninfected control (N2a) cells, the level of NICD was elevated in scrapie-infected neuroblastoma ( $\mathrm{ScN} 2 \mathrm{a})$ cells. $\mathrm{ScN} 2 \mathrm{a}$ cells exhibit short dendritic processes whereas non infected cells have long processes suggesting thus that $\mathrm{PrP}^{\mathrm{Sc}}$ activates Notch1 cleavage in $\mathrm{ScN} 2 \mathrm{a}$ cells $[61,62]$. Whether these abnormalities are the consequence of $a b-$ normal PrP metabolism remains to be proven. Despite the numerous uncertainties regarding the physiological function of $\operatorname{PrP}^{\mathrm{C}}$, the consequences of its conversion into $\mathrm{PrP}^{\mathrm{Sc}}$ could explain the synaptic dysfunctions occurring in prion diseases. Indeed, through recruitment and interactions with NCAM (Neural Cell Adhesion Molecule) at the neuronal surface, PrP is implicated in neurite outgrough via signal transduction pathways including the activation of Fyn kinases [17, 35, 109]. In another study it has been shown that the coupling of $\mathrm{PrP}^{\mathrm{C}}$ to Fyn is dependent on caveolin- 1 and is restricted to the fully $1 \mathrm{C} 11$ differentiated serotonergic or noradrenergic cells and occurs mainly at neuritis [83]. Taken together, alteration of these specific protein-protein interactions with receptors, ion channels and transporters, following the conversion of $\mathrm{PrP}^{\mathrm{C}}$ into $\mathrm{PrP}^{\mathrm{Sc}}$, may trigger the related cell-death cascade resulting in neuronal loss.

\section{NEURONAL LOSS}

The premature cell death of neurons is a typical feature of TSE. Nevertheless, the cellular pathways contributing to neuronal loss are far from being elucidated. Presence of cells bearing nuclear DNA fragments is a common feature in the brains of humans affected by prion diseases $[40,41]$. This is reminiscent of apoptosis described in rodent experimental scrapie. Even if autophagic cell death may be also incriminated (see below), there is no doubt that apoptosis is responsible for cerebral damage in prion infected brains, as exemplified by the succession of caspases activation (mainly caspase 3 ) occurring in the brains of mice with experimental scrapie and in the cerebellum of patients with sporadic CJD [41, 114]. Since $\operatorname{PrP}^{\mathrm{Sc}}$ accumulates in the CNS early during the course of the disease, this abnormal protein is supposed to be the toxic entity involved in the molecular mechanism leading to neurodegeneration. However, whether this misfolded protein is directly toxic is a matter of controversy. Other PrP species might be involved, and it is interesting to note 
that when the molecule is targeted to different cellular compartments, including the cytosol, nucleus, and mitochondria, it can adopt a misfolded and partially proteinase K-resistant conformation [50, 51, 71]. In addition, since some of $\operatorname{PrP}^{\mathrm{C}}$ functions are associated with anti-oxidant and/or anti-apoptotic activity, the neurological dysfunction observed in prion diseases could be due to an impairment of endogenous $\operatorname{PrP}^{C}$ metabolism. Microglial activation and the associated neuroinflammation may also be part of the mechanisms by which neurons die in prion disease but it is still poorly understood. We will try to address these different points in the following sections.

\subsection{Is $\operatorname{PrP}^{\mathrm{Sc}}$ neurotoxic?}

The involvement of $\mathrm{PrP}^{\mathrm{Sc}}$ in neurodegeneration is still an important and controversial issue. Some data indicate that neuronal cell death might be related to modifications of several cellular processes, including proteasome dysfunction, alterations in PrP maturation pathway and the unfolded protein response (see below). On the other hand, some studies suggest that $\mathrm{PrP}^{\mathrm{Sc}}$ is not neurotoxic per $s e$, since neurodegeneration is not always associated with the presence of $\operatorname{PrP}^{S c}[60,66]$. Other studies showed that the pro-apoptotic markers Fas and caspase 3 were upregulated early in the incubation period in the brain of prion infected mice prior to $\mathrm{PrP}^{\mathrm{Sc}}$ deposition and clinical signs [63]. As some cell death events may occur before extensive $\mathrm{PrP}^{\mathrm{Sc}}$ accumulation, the existence of a transient neurotoxic species, distinct from aggregated $\mathrm{PrP}^{\mathrm{Sc}}$ can be envisioned [74]. In cellular models, the role of $\mathrm{PrP}^{\mathrm{Sc}}$ in cell death is also difficult to analyze because in most cases, prion infection has little or no apparent effect on the cell viability or phenotype. It is probably linked to the establishment of a fine balance between prion propagation, prion synthesis and prion degradation (for review see [124]). Moreover, it appears difficult to recapitulate completely in vivo models of prion disease with in vitro cellular models. Nevertheless, recombinant human PrP90-231 folded in a structural ' $\mathrm{PrP}^{\mathrm{Sc}}$-like' conformation was shown to affect survival of SH-SY5Y cells, inducing a caspase-3 and p38-kinase dependent apoptosis [25]. Mature amyloid fibrils produced from full-length recombinant mammalian prion protein (rPrP) were also highly toxic to cultured cells and primary hippocampal and cerebella neurons [87]. In GT1 cells a pathological phenotype was observed with an increase in the number of apoptotic cells in the infected cultures $[85,110]$ and recently Cronier et al. reported that prion infection of primary cultured neurons and astrocytes induced neuronal cell death [27]. In several studies although it is controversial, $\operatorname{PrP}^{\mathrm{C}}$ expression seemed to be crucial for intracellular intra-neuronal toxicity. This has been demonstrated by Mallucci et al. in their study showing that glial cells accumulate $\mathrm{PrP}^{\mathrm{Sc}}$ but, this did not cause neurotoxicity if the neurons did not express $\operatorname{PrP}^{\mathrm{C}}$ [73]. Moreover, prion intracerebral injection into PrP knock-out mice grafted with neural tissue overexpressing PrP, induced specific TSE lesions only in the grafted area [8]. This suggests that only neurons expressing $\mathrm{PrP}^{\mathrm{C}}$ would be damaged by exogenous $\mathrm{PrP}^{\mathrm{Sc}}$.

\subsection{Transmembrane PrP, CtmPrP and NtmPrP}

PrP can be produced experimentally under three topological conformers: the regular plasma membrane glycosylphosphatidylinositol-anchored PrP (GPI-anchored $\mathrm{PrP})$, the transmembrane C-trans form (Ctm$\operatorname{PrP}$ ), for which the C-terminus part is in the endoplasmic reticulum (ER) lumen and the $\mathrm{N}$-trans transmembrane (NtmPrP) for which the $\mathrm{NH}_{2}$-terminus is in the ER lumen. In both of the latter forms, the transmembrane domain is represented by the hydrophobic domain between residues 110 and 135 . No study has been published linking NtmPrP to TSE pathology. Conversely, CtmPrP was detected in inherited Gerstmann Sträussler Scheinker syndrome (GSS) carrying the A117V mutation. The disease was linked to a change in structure of the A117V mutated $\operatorname{PrP}[9,55]$ resulting in an increase of the CtmPrP expression. CtmPrP is thus supposed to be an intermediate form involved in the neurodegenerative pathways, in the absence of $\mathrm{PrP}^{\mathrm{Sc}}$ entities. Besides, it has also been shown 
that $\mathrm{PrP}^{\mathrm{Sc}}$ accumulation can promote $\mathrm{CtmPrP}$ production suggesting that this isoform is a major determinant of the prion cell death pathway [56] (for review see [54]). The toxic effect of CtmPrP has also been studied using peptides (PrP peptides 118-135 and 105-132) whose sequences are encompassing the transmembrane hydrophobic domain. These peptides are able to induce the death of pure cortical neurons in vitro [52] as well as the death of retinal neurons in vivo [16] independently of PrP expression. This 118-135 PrP peptide, exhibited membrane fusogenic properties and its toxicity has been correlated with its high propensity to insert stably into and to destabilize cell membranes [94, 95]. This mechanism is independent of fibril formation and could reflect the effect of the transmembrane insertion of CtmPrP [52, 94]. A recent study confirmed these findings and described apoptotic events induced by $\mathrm{Ctm}$ PrP, as well as by the 118-135 PrP peptides, in oligodendroglial cells, in vitro [116]. The fact that antioxidant molecules, such as probucol, propylgallate, and promethazine can inhibit this apoptosis suggests that oxidative injuries contribute to the 118-135 PrP cytotoxicity [116] (see below for oxidative stress). Finally, in a recent report using cultured neurons from transgenic mice expressing CtmPrP (L9R$3 \mathrm{AV}$ ), the CtmPrP was shown to localize to the Golgi and not to the ER as described above [118], suggesting that a re-examination of the previous data is necessary.

\subsection{Cytosolic PrP and Nuclear PrP}

Using high-resolution cryoimmunogold electron microscopy in the mouse hippocampus, $\operatorname{PrP}^{\mathrm{C}}$ is detected in the standard biosynthetic trafficking pathway with a preferential localization in late endosomal compartments and on the plasma membrane of neurons and neuronal processes [81]. Unexpectedly, under normal conditions, PrP is also present in the cytosol in subpopulations of neurons in the hippocampus, neocortex and thalamus but not the cerebellum. This cytosolic PrP may have altered susceptibility to aggregation, suggesting also that these neurons might play a significant role in the prion pathogenesis [81]. These results emphasise the largely documented but fully controversial field of the toxic/non toxic/antiapoptotic/cytosolic/nuclear PrP protein. Indeed, wild-type $\operatorname{PrP}^{\mathrm{C}}$ molecules have been reported to be processed by the endoplasmic reticulum-associated degradation (ERAD) proteasome pathway [70] in the course of which they can be mislocated in the cytosol [125]. Dysfunction of the ER quality control machinery may result in an accumulation of PrP in the cytosol thus triggering a neuronal death cascade activation in the cytoplasm [70]. In addition, treatment of cultured cells with proteasome inhibitors induces the accumulation of an aggregated and nonglycosylated form of PrP in the cytoplasm. Interestingly, both $\mathrm{CtmPrP}$ and $\mathrm{NtmPrP}$ exhibit an important cytosolic region which may induce a potential toxic pathway. Moreover, it has recently been shown that the diseaseassociated prion protein specifically inhibits the proteolytic beta subunits of the $26 \mathrm{~S}$ proteasome and that there is an impairment of the ubiquitin-proteasome system (UPS) in prioninfected UPS-reporter mice [65]. This may in turn lead to an autostimulation of the cytosolic PrP accumulation. By contrast, other studies observed that neither wild-type or mutant PrP proteins were major substrates for retranslocation from the ER prior to proteasome degradation and that mutant PrP was only delayed in its exit from the ER [32]. However, artificial expression of a PrP construct lacking the $\mathrm{N}$-terminal signal sequence and the GPI anchor (23-230 PrP), therefore supposedly cytosolic, was found to be toxic to cultured cells [72]. Transgenic mice expressing the only 23-230 PrP, develop cerebellar degeneration, severe gliosis, and a neurological dysfunction resulting in a severe ataxia, characteristic of prion diseases [72]. It has therefore been suggested that mis-localization of $\mathrm{PrP}$ in the cytoplasm could be responsible for the pathogenesis of prion diseases. The toxic potential may be linked to the 115-156 internal domain of $\mathrm{PrP}$ and involves co-aggregation of cytosolic PrP with the cytosolic anti-apoptotic Bcl-2. This co-aggregation can be prevented 
by over-expression of the chaperones Hsp70 and Hsp40 thus interfering with PrP-induced apoptosis [102]. PrP is also subject to retrograde transport from the plasma membrane towards the ER compartment which has been shown to play a significant role in $\mathrm{PrP}^{\mathrm{Sc}}$ conversion [5]. Therefore, the presence of $\mathrm{PrP}^{\mathrm{Sc}}$ in the ER may lead to an accumulation of misfolded PrP molecules which could be subsequently mislocated in the cytoplasm.

Conflicting results have recently been reported; they showed that although proteasome inhibition resulted in accumulation of misfolded cytosolic $\mathrm{PrP}^{\mathrm{C}}$, as well as neurotoxicity, the level of proteasome inhibition, which was the one used by Ma et al., is too far from physiological levels that could occur during prion pathogenesis [64]. In another independent study, quantification of N2a viability in the presence of proteasome inhibitors showed that accumulation of aggregated forms was not toxic [42]. Finally, in contrast to its supposed pro-apoptotic role, cytosolic PrP was not toxic but rather protects against Bax-mediated cell death [104]. To add to these conflicting results, we have recently shown that the 23-230 PrP can be localized in the nucleus [28]. For this study, we have established several inducible cell lines expressing either wild-type PrP, 23-230 PrP, or a tagged 23-230 PrP using hippocampal Npl1 Prnp ${ }^{-/-}$cells [86] and neuroblastoma N2a cells. We found that in both cell lines, 23-230 PrP was mostly localized in the nuclei independently of the presence of nuclear localization signals $[28,50]$. There were no significant differences in the viability of the cells expressing 23-230 PrP raising again questions about the neurodegenerative phenomena observed in transgenic mice overexpressing 23-230 PrP [72]. This nuclear localization was also reminiscent to what we had previously observed in prion infected $\mathrm{N} 2 \mathrm{a}$ cells where $10 \%$ of the $\operatorname{PrP}^{\mathrm{Sc}}$ localized in the nucleus independently of proteasome inactivation [75]. Since small proteins can freely pass through the nuclear membrane and because 23-230 PrP has a molecular weight of $23 \mathrm{kDa}$, it could enter and exit the nucleus by passive diffusion or during cell division. As described for recombinant $\operatorname{PrP}$ [45] and for $\mathrm{PrP}^{\mathrm{Sc}}$ [75],
23-230 PrP binds to chromatin. This DNA binding capacity could explain the nuclear accumulation of 23-230 PrP. This is reminiscent of a truncated PrP mutant, PrP Q160 ${ }^{\text {Stop }}$, associated to a familial early onset dementia, which is almost exclusively localized in the nucleus of transfected cells [69]. We were also surprised that overexpression of a 23-230 PrP in the nucleus induces formation of multinucleated cells. This was the first demonstration that mis-localization of the prion protein can be associated to some extent with altered cytokinesis. The underlying mechanism responsible for 23-230 PrP-induced generation of multinucleated cells remains to be determined. Nevertheless, in a culture system, such multinucleated cells could result from multiple rounds of nuclear division without cytokinesis. Neurons in the adult brain are traditionally viewed as having permanently exited the cell cycle and entered a differentiated quiescent state. However, recent evidence shows that mature neurons can abnormally re-enter the cell cycle, which may be an important mechanism of cell death [24]. Recent studies of brain injuries or human neurodegenerative disorders such as Alzheimer's disease (AD) have discovered that bona fide cell cycle regulators were expressed in post mitotic neurons of affected brain regions, leading to successful DNA replication, but unsuccessful mitosis (for a review, see [123]). The accumulation of trior tetraploid nuclei in $\mathrm{AD}$ neurons indicates that degenerating neurons synthesize DNA but fail to undergo mitotic division, which leads to a critical sequence of events that could provoke neurodegeneration in AD. Consequently, 23-230 PrP expression might cause abnormal cell-cycle re-entry in post mitotic neurons, a mechanism which could explain the toxic effects of 23-230 PrP expression that has been observed in transgenic animals [72].

\section{4. $\mathrm{PrP}$ in aggresomes}

In a recent study Kritiansen et al., have shown that $\mathrm{PrP}^{\mathrm{Sc}}$ entities form aggresomes in neuronal cells resulting in caspase activation and apoptosis [64]. This was observed in prion infected N2a and GT-1 cells treated with mild levels of proteasome inhibitors to 
mimic what could be found during senescence or prion pathogenesis [65]. In this context, cells were susceptible to cell death (activation of caspases 3 and 8) whereas the non treated cells were not susceptible. Moreover, the cells accumulated large cytoplasmic perinuclear aggresomes structures containing $\mathrm{PrP}^{\mathrm{Sc}}$, Hsp70, ubiquitin, proteasome subunits and vimentin that were temporally associated with caspase 3 and 8 activation and subsequent apoptosis. A possible retranslocation of $\mathrm{PrP}^{\mathrm{Sc}}$ from the ER may be incriminated to explain the presence of $\mathrm{PrP}^{\mathrm{Sc}}$ in those structures [5]. However, and contrary to what was published by Ma et al. previously [72], cell death was neither observed in non infected cells nor in cells overexpressing high levels of cytoplasmic aggregating $\mathrm{PrP}^{\mathrm{C}}$. Interestingly, it had been previously shown that misfolded cytosolic PrP as well as pathogenic prion protein mutants were able to form aggresome in response to cyclosporin A and proteasome inhibition respectively $[22,82]$. In another study, immunofluorescence and electron microscopy have revealed that cytoplasmic PrP was localized in juxtanuclear aggregates reminiscent of aggresomes in human embryonic kidney 293 cells, human neuroblastoma BE2-M17 cells and mouse neuroblastoma N2a cells [49]. Time course studies revealed that discrete aggregates form first throughout the cytoplasm, and then coalesce to form an aggresome. In parallel, cytoplasmic PrP aggregates induced mitochondrial clustering, reorganization of intermediate filaments, preventing wild-type PrP secretion and promoting cell death [49]. It is likely that any event leading to accumulation of $\operatorname{PrP}$ in the cytoplasm is likely to result in cell death. On the other hand, a new emerging concept proposes that in proteinopathies, protein aggregates are not toxic per se and might even serve as a protective role by sequestering misfolded proteins in aggresomes. Specifically, experimental models of polyglutamine diseases, Alzheimer's disease, and Parkinson's disease revealed that the appearance of aggregates can be dissociated from neuronal toxicity. Misfolded monomers or oligomeric intermediates appear to be the more probable toxic species. This is consistent with recent data indicating that smaller subfibrillar particles with a mass equivalent to $14-28$ PrP molecules are the most infectious moiety and may be much more toxic than larger amyloid fibrils or plaques [113].

\subsection{Anchorless-PrP}

It was believed for a long time that expression of a GPI anchored $\operatorname{PrP}^{\mathrm{C}}$ was necessary for PrP function [115] or infection [103]. Amazingly, transgenic mice expressing only GPI anchorless-PrP could be infected with prions and accumulated high levels of $\mathrm{PrP}^{\mathrm{Sc}}$ and amyloid plaques associated with high prion titers, but they do not suffer neurodegeneration [18]. This result fits with the idea that $\mathrm{PrP}^{\mathrm{Sc}}$ is involved in a neurotoxic pathway that could be activated in endocytic compartment and/or at the plasma membrane and involve $\operatorname{PrP}^{\mathrm{C}}$, caveolin, Fyn kinases [111] and other partners that remain to be identified.

\subsection{Analysis of prion neurotoxicity using $\operatorname{PrP}$ peptides}

It is not clear whether the use of peptides such as PrP106-126 to mimic the physiopathology of TSE is really pertinent. However, the latter peptide shares many physicochemical properties with $\mathrm{PrP}^{\mathrm{Sc}}$, is neurotoxic in vitro and has been largely used to explore the neurotoxic mechanisms underlying TSE. Many types of PrP peptides have also been studied under multiple conditions and in many different cellular models. This complex situation is summarized in Table I where we have listed several studies in relation with cell death and PrP peptides.

Some results obtained with peptides were similar to those obtained with prion infection suggesting that peptides were able to activate pathways targeted when $\mathrm{PrP}^{\mathrm{Sc}}$ itself was present. A demonstrative example is the study of the apoptotic events induced by exposure to HuPrP106-126 peptide in primary culture of murine cortical neurons. The aggregated peptide indeed induced a massive neuronal death within $24 \mathrm{~h}$ while reactive oxygen species were detected after $3 \mathrm{~h}$ and were followed by a peak of phosphorylated c-Jun-N-terminal 


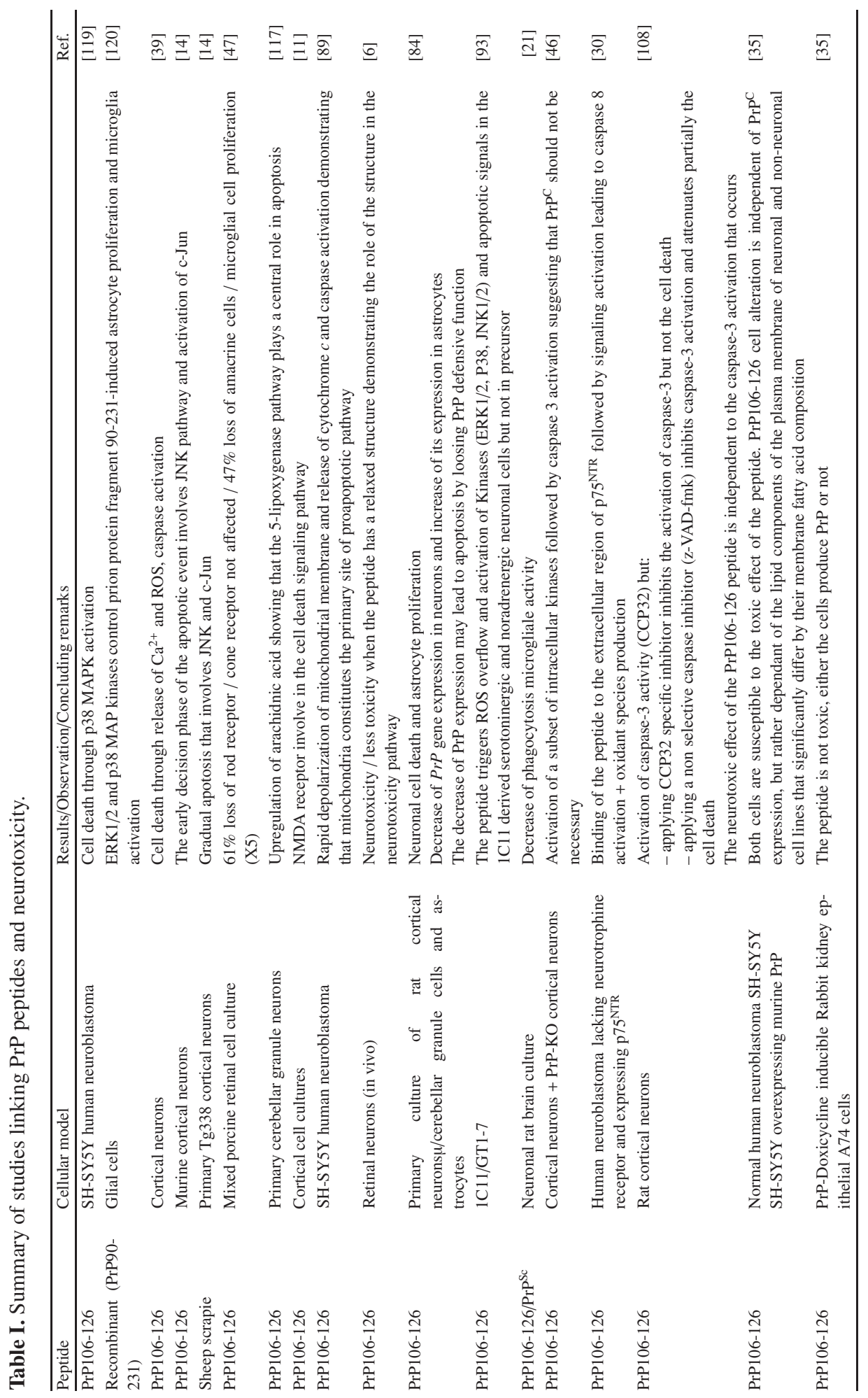


kinase (JNK) translocation into the nucleus after $8 \mathrm{~h}$, along with the activation of the nuclear c-Jun transcription factor [14]. The involvement of JNK in the early decision phase was confirmed in a more physiological model of prion infected primary tg 338 cortical neurons [27] but with a slight shift in time [14]. In this model the apoptosis gradually increased with time and induced a $40 \%$ cell death after two weeks exposure and the early c-Jun activation was detected after seven days [14].

\subsection{ER stress/ER apoptotic pathway}

Endoplasmic reticulum (ER) stress is caused by disturbances in the structure and function of the ER and is associated with the accumulation of misfolded proteins and alterations in the calcium homeostasis. The ER response is characterized by changes in specific proteins, causing translational attenuation, induction of ER chaperones and degradation of misfolded proteins. In case of prolonged or aggravated ER stress, cellular signals leading to cell death are activated. Castilla et al. [15] have proposed a general pathogenesis model of prion disorders based on the alteration of ERhomeostasis. This alteration could be due to drastic modifications of the biophysical properties of PrP, leading to the activation of ERdependent signalling pathways that controls cellular survival. Indeed, prion replication has been shown to trigger ER stress as reported by Hetz et al. [59]. In this study, purified $\mathrm{PrP}^{\mathrm{Sc}}$ extracted from mouse scrapie brain induced apoptosis of $\mathrm{N} 2$ a cells mediated by an increase of calcium release from ER and caspase 12 activation. The infected cells were in turn more susceptible to ER stress. The correlation between caspase 12 activation and neuronal loss was confirmed in models of prion infected mice as well as in CJD patients [57]. Moreover, Ferreiro et al. have recently shown that ER stress cell death induced by PrP peptides was also associated with calcium homeostasis perturbation [39]. They suggested that the early PrP-induced perturbation of ER $\mathrm{Ca}^{2+}$ homeostasis is a death message that leads to neuronal loss [39]. In addition, ER stress led to the generation of a misfolded PrP isoform, which was detergent-insoluble but protease- sensitive [58] suggesting that ER-damaged cells appear more susceptible to prion replication. This is emphasised also by results showing that ER stress conditions weaken PrP co-translational translocation, favouring accumulation of cytosolic PrP [91]. Finally, the PrP isoform generated after ER stress seemed more efficiently converted into $\mathrm{PrP}^{\mathrm{Sc}}$ in in vitro replication systems compared with the protein extracted from non ER damaged cells [58]. Since $\mathrm{PrP}^{\mathrm{Sc}}$ induces ER stress, there may be thus a positive feedback loop that could accelerate prion replication.

Finally, all these results should be considered with caution since no evidence of ER stress was found in histopathological studies of post-mortem brains of CJD patients [121].

\subsection{Autophagy}

While apoptosis may play a major role in the events leading to neuronal loss in TSE, autophagy was also identified in experimentally induced scrapie a long time ago, and was recently re-evaluated as a possible cell death program in prion diseases. Indeed, autophagy represents a common ultrastructural feature of TSE and autophagic vacuoles are frequently present in experimentally induced scrapie, CJD and GSS [112]. At the ultrastructural level, autophagy is represented by membrane sequestration of neuronal cytoplasm by concentric arrays of double membranes, membrane proliferation and the formation of autophagic vacuoles of various sizes in all parts of the neurons including synaptic endings. Finally, a large area of the cytoplasm was transformed into a collection of autophagic vacuoles of different sizes. On the basis of these studies, Liberski et al. have suggested that autophagy plays a major role in TSE and may even participate in the spongiform changes [68]. At the molecular level, Dron et al. [33,34], have shown that the Scrgl gene was upregulated in TSE. This gene encodes a protein associated with the Golgi apparatus as well as with autophagic vacuoles of degenerative neurons. The authors suggest that Scrgl is involved in the host response to stress and/or the death of neurons and could be used to follow autophagic 
events [33, 34]. However, increased numbers of autophagosomes/autophagic vacuoles are seen in a variety of physiological and pathological states in the nervous system. It is unclear if this phenomenon is the result of increased autophagic activity or decreased autophagosome-lysosome fusion. The functional significance of autophagy and its relationship to cell death in the nervous system is also poorly understood. While many issues remain unresolved, it raises the possibility that autophagy can have either deleterious or protective effects depending on the specific situation and stage in the pathological process [106]. It is also unclear whether the aggregated PrP enhances the autophagic activity as it has been proposed for the misfolded huntingtin protein $[78,106]$. In this particular case, autophagy constitutes an alternative route for the intracytosolic protein degradation or clearance of aggregated proteins when the ubiquitin-proteasome system is altered. This system could thus rescue toxicity mediated by proteasome inhibition and provide a protective effect $[78,106]$. Whether autophagy may first play a protective role in prion disease therefore needs to be analysed in more detail.

\subsection{Loss of $\operatorname{PrP}^{\mathrm{C}}$ function/interference with $\operatorname{PrP}^{\mathrm{C}}$ function}

Other hypothesises for prion induced cell death involved $\mathrm{PrP}^{\mathrm{C}}$ loss of function. This would occur when $\mathrm{PrP}^{\mathrm{C}}$ is converted into $\mathrm{PrP}^{\mathrm{Sc}}$, or if its normal function is subverted by its association with $\mathrm{PrP}^{\mathrm{Sc}}$. Even if the role of $\mathrm{PrP}^{\mathrm{C}}$ is not totally elucidated, there are many evidences that $\mathrm{PrP}^{\mathrm{C}}$ can exert a cytoprotective function through an anti-oxidant, as well as an anti-apoptotic activity. It is therefore easy to imagine that loss of these functions could directly increase susceptibility to oxidative stress and result in cell death. This is exemplified by studies reporting an increased susceptibility of PrP knock-out neuronal cells to oxidative stress [80]. Moreover, PrP exerts an anti-apoptotic function via its anti-Bax activity. As the Bax pro-apoptotic pathway seems to be implicated in neuronal death, as shown by Chiesa et al. in the inherited prion disease transgenic mouse model
$\operatorname{Tg}$ (PG14) [20,67], it is therefore tempting to propose that loss of this function will be a determinant for neuronal cell death. However, the Bax pathway is not an obligatory phenomenon [67] since in another study Coulpier et al. have reported that $\mathrm{Bax}^{-/-}$mice challenged with the BSE (Bovine spongiform encephalopathy) agent developed an unaltered prion disease in terms of neuronal loss [26]. To reconcile these data, a third study using transgenic mice showed that $\mathrm{N}$-terminally deleted forms of the prion protein activated both Baxdependent and Bax-independent neurotoxic pathways. Bax deletion in $\operatorname{Tg}(\operatorname{PrP} \Delta 32-134)$ mice delayed the development of clinical illness and slowed apoptosis of cerebellar granule cells but had no effect on white matter degeneration [67]. Bax deletion had also no effect in $\operatorname{Tg}(\operatorname{PrP} \Delta 105-125)$ mice [67] suggesting that the PrP deleted domains are important for the interaction with Bax cell-death signalling molecules. Altogether these studies suggest the existence of multiple molecular death pathways in prion diseases and that specific domains of PrP are essential for its neuroprotective activity. The anti-Bax function of $\mathrm{PrP}$, could be linked to $\mathrm{PrP}^{\mathrm{Sc}}$ conformation or at least to PrP sequence. For example, the ectopic expression of PrP protects primary neurons against Bax mediated cell death [105]. This activity is lost when $\operatorname{PrP}$ contains the familial mutation (D178N) associated with the genetic Fatal Familial Insomnia prion disease, suggesting again that the normal structure of the PrP protein is necessary to promote an antiBax function [105]. These results suggest that loss of anti-Bax activity could be deleterious in some prion diseases.

Another putative function of $\operatorname{PrP}^{\mathrm{C}}$ that could be lost during the development of the disease consists in copper binding and metabolism. In scrapie infected mice, levels of copper are modified and PrP copper binding decrease. Using radioactive copper $\left({ }^{64} \mathrm{Cu}\right)$ at physiological concentrations, Rachidi et al., have shown that prion infected cells display a marked reduction in copper binding [100]. These modifications of copper homeostasis may play an essential role in the pathogenesis process [101]. $\mathrm{PrP}^{\mathrm{C}}$ is also supposed to 
promote copper uptake into cells and to enhance copper incorporation into superoxide dismutase to regulate intracellular $\mathrm{Cu} / \mathrm{Zn}$ superoxide dismutase activity [12]. $\operatorname{PrP}^{\mathrm{C}}$ itself also exerts a superoxide dismutase (SOD) role [12] and appears to serve as a stress sensor that is sensitive to copper and is able to initiate, following copper binding, a signal transduction process acting on the anti-oxidant systems to improve cell defences [101]. Conversion of $\mathrm{PrP}^{\mathrm{C}}$ into $\mathrm{PrP}^{\mathrm{Sc}}$ could alter this function and result in the loss of anti-oxidant defences [100]. In addition as abnormal protein accumulates in the injured brain, there is an increase of oxidative substances such as reactive oxygen species (ROS) (for review see [80]). The loss of the anti-oxidant defences will increase cell susceptibility to oxidative substances and therefore promotes cell death. This is in accordance with data reporting that prion infection renders neuronal cells more susceptible to oxidative stress and impairs their free radical metabolism promoting neuronal damages [14, 79]. However, $\operatorname{PrP}^{\mathrm{Sc}}$ could affect the putative role of PrP in the defence against oxidative stress in many different ways: $\mathrm{PrP}^{\mathrm{Sc}}$ could compete with $\mathrm{PrP}^{\mathrm{C}}$ by binding to $\mathrm{PrP}^{\mathrm{C}}$ or $\mathrm{PrP}^{\mathrm{C}}$ putative co-receptors involved in PrP-dependent signalling and could lead to the opposite effect that was expected. The inhibition of the signalling pathway may result in the down regulation of the different defences (SOD, etc) against oxidative stress. As one illustration, it has been shown that the neurotoxic action of PrP106-126 peptide relies on cell surface expression of $\operatorname{PrP}^{\mathrm{C}}$, recruitment of a $\operatorname{PrP}^{\mathrm{C}}$-Caveolin-Fyn signalling pathway, and over stimulation of NADPH-oxidase activity causing oxidative injury of bioaminergic neuronal cells $[93,111]$. PrP106-126-induced neuronal injury appears to be caused by an aberrant amplification of $\mathrm{PrP}^{\mathrm{C}}$-associated signalling responses, which in turn promote oxidative stress conditions [93]. In the same idea, $\mathrm{PrP}^{\mathrm{Sc}}$ production might subvert $\mathrm{PrP}^{\mathrm{C}}$ function by cross-linking $\operatorname{PrP}^{\mathrm{C}}$ at the cell surface thus promoting cell death [115]. $\mathrm{PrP}^{\mathrm{Sc}}$ 'gain of function' could also lead, by itself and independently of $\operatorname{PrP}^{\mathrm{C}}$ function, to an increase of intracellular ROS. ROS would impair the response of the cells to oxidative stress, inhibiting or destroying important anti-oxidant enzymes $[1,90]$. In addition this scenario could be a consequence of the two previous possibilities and could even be amplified by the activation of microglial cells by $\mathrm{PrP}^{\mathrm{Sc}}$ and the release by these cells of significant amounts of ROS. These changes create a paradox because the loss of activity is not accompanied by a loss of PrP expression and PrP knock-out mice have no pathologic phenotype. However, activation of microglial cells by $\operatorname{PrP}^{\mathrm{Sc}}$ and the associated increase of ROS production could explain the lack of this strong phenotype for PrP knock-out mice. For a revue, see Harris and True [53].

\subsection{Inflammation and microglia}

The contribution of inflammation to the progression of prion diseases is poorly understood. The inflammatory response is mediated by the activated microglia, the resident immune cells of the CNS, which normally respond to neuronal damage and remove the damaged cells by phagocytosis. However, the chronic activation of microglia may cause neuronal damage through the release of potentially cytotoxic molecules such as proinflammatory cytokines, ROS, proteases, and complement proteins [19]. Both in experimental and natural TSE it has been shown that activation of microglial cells and astrocytes is a common and early physiopathogenic event during the course of the disease [98]. These features have been modelled in vitro upon exposure of neuronal and glial cultures to $\mathrm{PrPSc}^{\mathrm{Sc}}$ or to PrP peptides. For example the PrP82-146 peptide was shown to exert a gliotrophic activity by inducing astrocyte proliferation [43]. The PrP106-126 peptide also elicited a specific over-production of pro-inflammatory cytokines IL-1 $\beta$ and IL-6 in microglial cells (but not an increased expression of TNF- $\alpha$, IL-10, or TGF- $\beta 1$ ) [92]. These effects were strictly dependent on the ability of the peptide to form amyloid fibrils. The microglial reaction also appears to be related to the biochemical type and deposition pattern of $\mathrm{PrP}^{\mathrm{Sc}}$. In Human, strong microglial activation was shown to be associated with type $1 \mathrm{PrP}^{\mathrm{Sc}}$ and diffuse $\mathrm{PrP}$ 
immunoreactivity, whereas type $2 \mathrm{PrP}^{\mathrm{Sc}}$ and focal PrP deposits were accompanied by mild microglial reaction [99]. In another study, the toxic effect induced by PrP106-126 peptide on neuronal cultures can be amplified in the presence of microglial cells which responds to the peptide by producing ROS [10]. It was also shown that this peptide triggered the expression of the inducible form of NOS (Nitric oxide synthase) in a TNF- $\alpha$-dependent manner involving p38 MAPK (Mitogen-Activated Protein Kinases) [37] in microglia and that the nitric oxide release was responsible, at least in part, to neuronal cell death [10]. To respond to these cytokines and oxidative species, several surface receptors need to be activated. One of them, the neuronal p75 neurotrophin receptor $\left(\mathrm{p} 75^{\mathrm{NTR}}\right)$ has been already identified [30]. This receptor responds to pro-inflammatory cytokines such as TNF- $\alpha$ and IL- $1 \beta$ released from PrP106-126 treated microglia and kills SK-N-BE human neuroblastoma cells via its intracellular 'death' domain [30]. On the other hand, a bidirectional neuron-microglia crosstalk is necessary since microglial cells were shown to kill neurons in vitro through a microglial CD14-dependent process in reaction to a neuron specific phenotype arising only following PrP106-126 treatment [4]. Because reactive microglia are frequently present in the vicinity of PrPres aggregates [76], the recruitment of microglia is supposed to be one of the early steps of TSE pathogenesis. This recruitment appears to be under the control of chemokines acting through the activation of specific G-protein-coupled receptors. It has been shown in vitro and in vivo, that PrPres exposure induced the up-regulation of the chemokine RANTES through MAPkinase/ERK1/2 pathways inducing Elk-1 phosphorylation and RANTES transcription factor Egr-1 expression $[76,77]$. This lead to a rapid microglial migration as a result of chemokine receptor-5 (CCR-5) activation. When recruited in the vicinity of prion infected neurons, activated microglia may therefore cause neuronal cell damages $[76,77]$.

In addition, as 'macrophage' of the central nervous system, the phagocytic capacity of microglia is well recognized, and involvement of microglia in the removal and processing of amyloid fibrils was thought possible, thus preventing the harmful effect of the amyloid fibrils. Supporting this concept, recent data is demonstrating that 'pharmacogenetic' ablation of microglia from infected organotypic brain slices provoked an increase of $\mathrm{PrP}^{\mathrm{Sc}}$ levels, as well as an increase in susceptibility to infection [38]. However, fibrillar prion peptide (106-126) and scrapie prion protein were shown to hamper phagocytosis in microglia [21]. Altogether, this suggests that the extensive microglial activation accompanying prion diseases represents an efficient defensive reaction at least in a particular time frame.

\section{CONCLUSION}

Many questions concerning the role of PrP in the neurodegeneration pathways remain to be answered. The situation is complex as many interconnected pathways may be involved and interfere with each other: $\operatorname{PrP}^{\mathrm{C}}$ loss of function and $\mathrm{PrP}^{\mathrm{Sc}}$ acquisition of new toxic properties, proteasome alteration, ER-stress activation, autophagy, microglial activation in response to $\mathrm{PrP}^{\mathrm{Sc}}$ or the release of ROS, etc. It is possible that infected cells try to set up different means to overcome or fight $\mathrm{PrP}^{\mathrm{Sc}}$ accumulation but each of them seems to be limited and can in turn exert a deleterious effect contributing finally to cell death.

Acknowledgements. We thank Andrew Goldsborough for his advices and corrections. Supported by grants from the "GIS Infections à Prion", the EU Commission program NEUROPRION (FOOD-CT-2004-506579), the DEFRA project SE2002 and the CNRS.

\section{REFERENCES}

[1] Asahi M., Fujii J., Suzuki K., Seo H.G., Kuzuya T., Hori M., et al., Inactivation of glutathione peroxidase by nitric oxide. Implication for cytotoxicity, J. Biol. Chem. (1995) 270:21035-21039.

[2] Bareggi S.R., Braida D., Gervasoni M., Carcassola G., Pollera C., Verzoni C., Sala M., Neurochemical and behavioural modifications induced by scrapie infection in golden hamsters, Brain Res. (2003) 984:237-241.

[3] Bassant M.H., Picard M., Olichon D., Cathala F., Court L., Changes in the serotonergic, noradrenergic and dopaminergic levels in the brain of scrapieinfected rats, Brain Res. (1986) 367:360-363.

[4] Bate C., Reid S., Williams A., Killing of priondamaged neurones by microglia, Neuroreport (2001) 12:2589-2594. 
[5] Béranger F., Mangé A., Goud B., Lehmann S., Stimulation of $\mathrm{PrP}^{\mathrm{C}}$ retrograde transport toward the endoplasmic reticulum increases accumulation of $\operatorname{PrP}(\mathrm{Sc})$ in prion-infected cells, J. Biol. Chem. (2002) 277:38972-38977.

[6] Bergström A.L., Cordes H., Zsurger N., Heegaard P.M., Laursen H., Chabry J., Amidation and structure relaxation abolish the neurotoxicity of the prion peptide PrP106-126 in vivo and in vitro, J. Biol. Chem. (2005) 280:23114-23121.

[7] Bouzamondo-Bernstein E., Hopkins S.D., Spilman P., Uyehara-Lock J., Deering C., Safar J., et al., The neurodegeneration sequence in prion diseases: evidence from functional, morphological and ultrastructural studies of the GABAergic system, J. Neuropathol. Exp. Neurol. (2004) 63:882-899.

[8] Brandner S., Isenmann S., Raeber A., Fischer M., Sailer A., Kobayashi Y., et al., Normal host prion protein necessary for scrapie-induced neurotoxicity, Nature (1996) 379:339-343.

[9] Bratosiewicz-Wasik J., Wasik T.J., Liberski P.P., Molecular approaches to mechanisms of prion diseases, Folia Neuropathol. (2004) 42 Suppl A:33-46.

[10] Brown D.R., Schmidt B., Kretzschmar H.A., Role of microglia and host prion protein in neurotoxicity of a prion protein fragment, Nature (1996) 380:345-347.

[11] Brown D.R., Schmidt B., Kretzschmar H.A., Effects of oxidative stress on prion protein expression in PC12 cells, Int. J. Dev. Neurosci. (1997) 15:961972.

[12] Brown D.R., Besinger A., Prion protein expression and superoxide dismutase activity, Biochem. J. (1998) 334:423-429.

[13] Bruce M.E., McBride P.A., Jeffrey M., Scott J.R., PrP in pathology and pathogenesis in scrapie-infected mice, Mol. Neurobiol. (1994) 8:105-112.

[14] Carimalo J., Cronier S., Petit G., Peyrin J.M., Boukhtouche F., Arbez N., et al., Activation of the JNK-c-Jun pathway during the early phase of neuronal apoptosis induced by PrP106-126 and prion infection, Eur. J. Neurosci. (2005) 21:2311-2319.

[15] Castilla J., Hetz C., Soto C., Molecular mechanisms of neurotoxicity of pathological prion protein, Curr. Mol. Med. (2004) 4:397-403.

[16] Chabry J., Ratsimanohatra C., Sponne I., Elena P.P., Vincent J.P., Pillot T., In vivo and in vitro neurotoxicity of the human prion protein (PrP) fragment P118-135 independently of PrP expression, J. Neurosci. (2003) 23:462-469.

[17] Chen S., Mangé A., Dong L., Lehmann S., Schachner M., Prion protein as trans-interacting partner for neurons is involved in neurite outgrowth and neuronal survival, Mol. Cell. Neurosci. (2003) 22:227233.

[18] Chesebro B., Trifilo M., Race R., Meade-White K., Teng C., LaCasse R., et al., Anchorless prion protein results in infectious amyloid disease without clinical scrapie, Science (2005) 308:1435-1439.
[19] Chiarini A., Dal Pra I., Whitfield J.F., Armato U., The killing of neurons by beta-amyloid peptides, prions, and pro-inflammatory cytokines, Ital. J. Anat. Embryol. (2006) 111:221-246.

[20] Chiesa R., Piccardo P., Dossena S., Nowoslawski L., Roth K.A., Ghetti B., Harris D.A., Bax deletion prevents neuronal loss but not neurological symptoms in a transgenic model of inherited prion disease, Proc. Natl. Acad. Sci. U.S.A. (2005) 102:238-243.

[21] Ciesielski-Treska J., Grant N.J., Ulrich G., Corrotte M., Bailly Y., Haeberle A.M., et al., Fibrillar prion peptide (106-126) and scrapie prion protein hamper phagocytosis in microglia, Glia (2004) 46:101115.

[22] Cohen E., Taraboulos A., Scrapie-like prion protein accumulates in aggresomes of cyclosporin Atreated cells, EMBO J. (2003) 22:404-417.

[23] Collinge J., Whittington M.A., Sidle K.C., Smith C.J., Palmer M.S., Clarke A.R., Jefferys J.G., Prion protein is necessary for normal synaptic function, Nature (1994) 370:295-297.

[24] Copani A., Uberti D., Sortino M.A., Bruno V., Nicoletti F., Memo M., Activation of cell-cycleassociated proteins in neuronal death: a mandatory or dispensable path?, Trends Neurosci. (2001) 24:25-31.

[25] Corsaro A., Thellung S., Villa V., Principe D.R., Paludi D., Arena S., et al., Prion protein fragment 106126 induces a p38 MAP kinase-dependent apoptosis in SH-SY5Y neuroblastoma cells independently from the amyloid fibril formation, Ann. N. Y. Acad. Sci. (2003) 1010:610-622.

[26] Coulpier M., Messiaen S., Hamel R., Fernández de Marco M., Lilin T., Eloit M., Bax deletion does not protect neurons from BSE-induced death, Neurobiol. Dis. (2006) 23:603-611.

[27] Cronier S., Laude H., Peyrin J.M., Prions can infect primary cultured neurons and astrocytes and promote neuronal cell death, Proc. Natl. Acad. Sci. USA (2004) 101:12271-12276.

[28] Crozet C., Vézilier J., Delfieu V., Nishimura T., Onodera T., Casanova D., et al., The truncated 23230 form of the prion protein localizes to the nuclei of inducible cell lines independently of its nuclear localization signals and is not cytotoxic, Mol. Cell. Neurosci. (2006) 32:315-323.

[29] Cunningham C., Deacon R., Wells H., Boche D., Waters S., Diniz C.P., et al., Synaptic changes characterize early behavioural signs in the ME7 model of murine prion disease, Eur. J. Neurosci. (2003) 17:2147-2155.

[30] Della-Bianca V., Rossi F., Armato U., Dal-Pra I., Costantini C., Perini G., et al., Neurotrophin p75 receptor is involved in neuronal damage by prion peptide-(106-126), J. Biol. Chem. (2001) 276:38929_ 38933.

[31] Diez M., Groth D., DeArmond S.J., Prusiner S.B., Hökfelt T., Changes in neuropeptide expression in mice infected with prions, Neurobiol. Aging (2007) 28:748-765. 
[32] Drisaldi B., Stewart R.S., Adles C., Stewart L.R., Quaglio E., Biasini E., et al., Mutant PrP is delayed in its exit from the endoplasmic reticulum, but neither wild-type nor mutant PrP undergoes retrotranslocation prior to proteasomal degradation, J. Biol. Chem. (2003) 278:21732-21743.

[33] Dron M., Bailly Y., Beringue V., Haeberlé A.M., Griffond B., Risold P.Y., et al., Scrg1 is induced in TSE and brain injuries, and associated with autophagy, Eur. J. Neurosci. (2005) 22:133-146.

[34] Dron M., Bailly Y., Beringue V., Haeberlé A.M., Griffond B., Risold P.Y., et al., Scrg1, a potential marker of autophagy in transmissible spongiform encephalopathies, Autophagy (2006) 2:58-60.

[35] Dupiereux I., Zorzi W., Rachidi W., Zorzi D., Pierard O., Lhereux B., et al., Study on the toxic mechanism of prion protein peptide 106-126 in neuronal and non neuronal cells, J. Neurosci. Res. (2006) 84:637646.

[36] Ersdal C., Simmons M.M., González L., Goodsir C.M., Martin S., Jeffrey M., Relationships between ultrastructural scrapie pathology and patterns of abnormal prion protein accumulation, Acta Neuropathol. (2004) 107:428-438.

[37] Fabrizi C., Silei V., Menegazzi M., Salmona M., Bugiani O., Tagliavini F., et al., The stimulation of inducible nitric-oxide synthase by the prion protein fragment 106-126 in human microglia is tumor necrosis factor-alpha-dependent and involves p38 mitogen-activated protein kinase, J. Biol. Chem. (2001) 276:25692-25696.

[38] Falsig J., Julius C., Margalith I., Schwarz P., Heppner F.L., Aguzzi A., A versatile prion replication assay in organotypic brain slices, Nat. Neurosci. (2008) 11:109-117.

[39] Ferreiro E., Oliveira C.R., Pereira C., Involvement of endoplasmic reticulum $\mathrm{Ca}^{2+}$ release through ryanodine and inositol 1,4,5-triphosphate receptors in the neurotoxic effects induced by the amyloid-beta peptide, J. Neurosci. Res. (2004) 76:872-880.

[40] Ferrer I., Nuclear DNA fragmentation in Creutzfeldt-Jakob disease: does a mere positive in situ nuclear end-labeling indicate apoptosis?, Acta Neuropathol (1999) 97:5-12.

[41] Ferrer I., Synaptic pathology and cell death in the cerebellum in Creutzfeldt-Jakob disease, Cerebellum (2002) 1:213-222.

[42] Fioriti L., Dossena S., Stewart L.R., Stewart R.S., Harris D.A., Forloni G., Chiesa R., Cytosolic prion protein (PrP) is not toxic in N2a cells and primary neurons expressing pathogenic PrP mutations, J. Biol. Chem. (2005) 280:11320-11328.

[43] Fioriti L., Angeretti N., Colombo L., De Luigi A., Colombo A., Manzoni C., et al., Neurotoxic and gliotrophic activity of a synthetic peptide homologous to Gerstmann-Sträussler-Scheinker disease amyloid protein, J. Neurosci. (2007) 27:1576-1583.

[44] Fraser E., McDonagh A.M., Head M., Bishop M., Ironside J.W., Mann D.M., Neuronal and astrocytic responses involving the serotonergic system in human spongiform encephalopathies, Neuropathol. Appl. Neurobiol. (2003) 29:482-495.

[45] Gabus C., Auxilien S., Péchoux C., Dormont D., Swietnicki W., Morillas M., et al., The prion protein has DNA strand transfer properties similar to retroviral nucleocapsid protein, J. Mol. Biol. (2001) 307:10111021.

[46] Gavín R., Braun N., Nicolas O., Parra B., Ureña J.M., Mingorance A., et al., PrP(106-126) activates neuronal intracellular kinases and Egr1 synthesis through activation of NADPH-oxidase independently of PrPC , FEBS Lett. (2005) 579:4099-4106.

[47] Gong J., Jellali A., Forster V., Mutterer J., Dubus E., Altrock W.D., et al., The toxicity of the PrP106-126 prion peptide on cultured photoreceptors correlates with the prion protein distribution in the mammalian and human retina, Am. J. Pathol. (2007) 170:1314 1324 .

[48] Goudsmit J., Rohwer R.G., Silbergeld E.K., Gajdusek D.C., Hypersensitivity to central serotonin receptor activation in scrapie-infected hamsters and the effect of serotonergic drugs on scrapie symptoms, Brain Res. (1981) 220:372-377.

[49] Grenier C., Bissonnette C., Volkov L., Roucou X., Molecular morphology and toxicity of cytoplasmic prion protein aggregates in neuronal and non-neuronal cells, J. Neurochem. (2006) 97:1456-1466.

[50] Gu Y., Hinnerwisch J., Fredricks R., Kalepu S., Mishra R.S., Singh N., Identification of cryptic nuclear localization signals in the prion protein, Neurobiol. Dis. (2003) 12:133-149.

[51] Hachiya N.S., Yamada M., Watanabe K., Jozuka A., Ohkubo T., Sano K., et al., Mitochondrial localization of cellular prion protein $\left(\mathrm{PrP}^{\mathrm{C}}\right)$ invokes neuronal apoptosis in aged transgenic mice overexpressing $\mathrm{PrP}^{\mathrm{C}}$, Neurosci. Lett. (2005) 374:98-103.

[52] Haïk S., Peyrin J.M., Lins L., Rosseneu M.Y., Brasseur R., Langeveld J.P., et al., Neurotoxicity of the putative transmembrane domain of the prion protein, Neurobiol. Dis. (2000) 7:644-656.

[53] Harris D.A., True H.L., New insights into prion structure and toxicity, Neuron (2006) 50:353-357.

[54] Harrison C.F., Barnham K.J., Hill A.F., Neurotoxic species in prion disease: a role for PrP isoforms?, J. Neurochem. (2007) 103:1709-1720.

[55] Hegde R.S., Mastrianni J.A., Scott M.R., DeFea K.A., Tremblay P., Torchia M., et al., A transmembrane form of the prion protein in neurodegenerative disease, Science (1998) 279:827-834.

[56] Hegde R.S., Tremblay P., Groth D., DeArmond S.J., Prusiner S.B., Lingappa V.R., Transmissible and genetic prion diseases share a common pathway of neurodegeneration, Nature (1999) 402:822-826.

[57] Hetz C., Russelakis-Carneiro M., Maundrell K., Castilla J., Soto C., Caspase-12 and endoplasmic reticulum stress mediate neurotoxicity of pathological prion protein, EMBO J. (2003) 22:5435-5445. 
[58] Hetz C., Castilla J., Soto C., Perturbation of endoplasmic reticulum homeostasis facilitates prion replication, J. Biol. Chem. (2007) 282:12725-12733.

[59] Hetz C.A., Soto C., Stressing out the ER: a role of the unfolded protein response in prion-related disorders, Curr. Mol. Med. (2006) 6:37-43.

[60] Hsiao K.K., Groth D., Scott M., Yang S.L., Serban H., Rapp D., et al., Serial transmission in rodents of neurodegeneration from transgenic mice expressing mutant prion protein, Proc. Natl. Acad. Sci. USA (1994) 91:9126-9130.

[61] Ishikura N., Clever J.L., Bouzamondo-Bernstein E., Samayoa E., Prusiner S.B., Huang E.J., DeArmond S.J., Notch-1 activation and dendritic atrophy in prion disease, Proc. Natl. Acad. Sci. USA (2005) 102:886891.

[62] Ishikura N., Notch-1 is involved in neurodegeneration in prion diseases, Nippon Rinsho (2007) 65:1397-1400 (in Japanese).

[63] Jamieson E., Jeffrey M., Ironside J.W., Fraser J.R., Apoptosis and dendritic dysfunction precede prion protein accumulation in $87 \mathrm{~V}$ scrapie, Neuroreport (2001) 12:2147-2153.

[64] Kristiansen M., Messenger M.J., Klöhn P.C., Brandner S., Wadsworth J.D., Collinge J., Tabrizi S.J., Disease-related prion protein forms aggresomes in neuronal cells leading to caspase activation and apoptosis, J. Biol. Chem. (2005) 280:38851-38861.

[65] Kristiansen M., Deriziotis P., Dimcheff D.E., Jackson G.S., Ovaa H., Naumann H., et al., Diseaseassociated prion protein oligomers inhibit the $26 \mathrm{~S}$ proteasome, Mol. Cell (2007) 26:175-188.

[66] Lasmézas C.I., Deslys J.P., Robain O., Jaegly A., Beringue V., Peyrin J.M., et al., Transmission of the BSE agent to mice in the absence of detectable abnormal prion protein, Science (1997) 275:402-405.

[67] Li A., Barmada S.J., Roth K.A., Harris D.A., Nterminally deleted forms of the prion protein activate both Bax-dependent and Bax-independent neurotoxic pathways, J. Neurosci. (2007) 27:852-859.

[68] Liberski P.P., Sikorska B., Bratosiewicz-Wasik J., Gajdusek D.C., Brown P., Neuronal cell death in transmissible spongiform encephalopathies (prion diseases) revisited: from apoptosis to autophagy, Int. J. Biochem. Cell Biol. (2004) 36:2473-2490.

[69] Lorenz H., Windl O., Kretzschmar H.A., Cellular phenotyping of secretory and nuclear prion proteins associated with inherited prion diseases, J. Biol. Chem. (2002) 277:8508-8516.

[70] Ma J., Lindquist S., Wild-type PrP and a mutant associated with prion disease are subject to retrograde transport and proteasome degradation, Proc. Natl. Acad. Sci. USA (2001) 98:14955-14960.

[71] Ma J., Lindquist S., Conversion of PrP to a selfperpetuating $\mathrm{PrP}^{\mathrm{Sc}}$-like conformation in the cytosol, Science (2002) 298:1785-1788.
[72] Ma J., Wollmann R., Lindquist S., Neurotoxicity and neurodegeneration when PrP accumulates in the cytosol, Science (2002) 298:1781-1785.

[73] Mallucci G., Dickinson A., Linehan J., Klöhn P.C., Brandner S., Collinge J., et al., Depleting neuronal $\mathrm{PrP}$ in prion infection prevents disease and reverses spongiosis, Science (2003) 302:871-874.

[74] Mallucci G.R., White M.D., Farmer M., Dickinson A., Khatun H., Powell A.D., et al., Targeting cellular prion protein reverses early cognitive deficits and neurophysiological dysfunction in prion-infected mice, Neuron (2007) 53:325-335.

[75] Mangé A., Crozet C., Lehmann S., Béranger F., Scrapie-like prion protein is translocated to the nuclei of infected cells independently of proteasome inhibition and interacts with chromatin, J. Cell. Sci. (2004) 117:2411-2416.

[76] Marella M., Chabry J., Neurons and astrocytes respond to prion infection by inducing microglia recruitment, J. Neurosci. (2004) 24:620-627.

[77] Marella M., Gaggioli C., Batoz M., Deckert M., Tartare-Deckert S., Chabry J., Pathological prion protein exposure switches on neuronal mitogen-activated protein kinase pathway resulting in microglia recruitment, J. Biol. Chem. (2005) 280:1529-1534.

[78] Menzies F.M., Ravikumar B., Rubinsztein D.C., Protective roles for induction of autophagy in multiple proteinopathies, Autophagy (2006) 2:224-225.

[79] Milhavet O., McMahon H.E., Rachidi W., Nishida N., Katamine S., Mangé A., et al., Prion infection impairs the cellular response to oxidative stress, Proc. Natl. Acad. Sci. USA (2000) 97:13937-13942.

[80] Milhavet O., Lehmann S., Oxidative stress and the prion protein in transmissible spongiform encephalopathies, Brain Res. Brain Res. Rev. (2002) 38:328-339.

[81] Mironov A. Jr., Latawiec D., Wille H., Bouzamondo-Bernstein E., Legname G., Williamson R.A., et al., Cytosolic prion protein in neurons, J. Neurosci. (2003) 23:7183-7193.

[82] Mishra R.S., Bose S., Gu Y., Li R., Singh N., Aggresome formation by mutant prion proteins: the unfolding role of proteasomes in familial prion disorders, J. Alzheimers Dis. (2003) 5:15-23.

[83] Mouillet-Richard S., Ermonval M., Chebassier C., Laplanche J.L., Lehmann S., Launay J.M., Kellermann O., Signal transduction through prion protein, Science (2000) 289:1925-1928.

[84] Ning Z.Y., Zhao D.M., Liu H.X., Yang J.M., Han C.X., Cui Y.L., et al., Altered expression of the prion gene in rat astrocyte and neuron cultures treated with prion peptide 106-126, Cell. Mol. Neurobiol. (2005) 25:1171-1183.

[85] Nishida N., Harris D.A., Vilette D., Laude H., Frobert Y., Grassi J., et al., Successful transmission of three mouse-adapted scrapie strains to murine neuroblastoma cell lines overexpressing wild-type mouse prion protein, J. Virol. (2000) 74:320-325. 
[86] Nishimura T., Sakudo A., Hashiyama Y., Yachi A., Saeki K., Matsumoto Y., et al., Serum withdrawalinduced apoptosis in $\mathrm{ZrchI}$ prion protein (PrP) genedeficient neuronal cell line is suppressed by $\operatorname{PrP}$, independent of Doppel, Microbiol. Immunol. (2007) 51:457-466.

[87] Novitskaya V., Bocharova O.V., Bronstein I., Baskakov I.V., Amyloid fibrils of mammalian prion protein are highly toxic to cultured cells and primary neurons, J. Biol. Chem. (2006) 281:13828-13836.

[88] Novitskaya V., Makarava N., Sylvester I., Bronstein I.B., Baskakov I.V., Amyloid fibrils of mammalian prion protein induce axonal degeneration in NTERA2-derived terminally differentiated neurons, J. Neurochem. (2007) 102:398-407.

[89] O'Donovan C.N., Tobin D., Cotter T.G., Prion protein fragment PrP-(106-126) induces apoptosis via mitochondrial disruption in human neuronal SH-SY5Y cells, J. Biol. Chem. (2001) 276:43516-43523.

[90] Ookawara T., Kawamura N., Kitagawa Y., Taniguchi N., Site-specific and random fragmentation of $\mathrm{Cu}, \mathrm{Zn}$-superoxide dismutase by glycation reaction. Implication of reactive oxygen species, J. Biol. Chem. (1992) 267:18505-18510.

[91] Orsi A., Fioriti L., Chiesa R., Sitia R., Conditions of endoplasmic reticulum stress favor the accumulation of cytosolic prion protein, J. Biol. Chem. (2006) 281:30431-30438.

[92] Peyrin J.M., Lasmézas C.I., Haïk S., Tagliavini F., Salmona M., Williams A., et al., Microglial cells respond to amyloidogenic PrP peptide by the production of inflammatory cytokines, Neuroreport (1999) 10:723-729.

[93] Pietri M., Caprini A., Mouillet-Richard S., Pradines E., Ermonval M., Grassi J., et al., Overstimulation of $\mathrm{PrP}^{\mathrm{C}}$ signaling pathways by prion peptide 106-126 causes oxidative injury of bioaminergic neuronal cells, J. Biol. Chem. (2006) 281:28470-28479.

[94] Pillot T., Lins L., Goethals M., Vanloo B., Baert J., Vandekerckhove J., et al., The $118-135$ peptide of the human prion protein forms amyloid fibrils and induces liposome fusion, J. Mol. Biol. (1997) 274:381-393.

[95] Pillot T., Drouet B., Pinçon-Raymond M., Vandekerckhove J., Rosseneu M., Chambaz J., A nonfibrillar form of the fusogenic prion protein fragment (118-135) induces apoptotic cell death in rat cortical neurons, J. Neurochem. (2000) 75:2298-2308.

[96] Prusiner S.B., Novel proteinaceous infectious particles cause scrapie, Science (1982) 216:136-144.

[97] Prusiner S.B., DeArmond S.J., Prion diseases of the central nervous system, Monogr. Pathol. (1990) 86-122.

[98] Prusiner S.B., Biology and genetics of prion diseases, Annu. Rev. Microbiol. (1994) 48:655-686.

[99] Puoti G., Giaccone G., Mangieri M., Limido L., Fociani P., Zerbi P., et al., Sporadic Creutzfeldt-Jakob disease: the extent of microglia activation is dependent on the biochemical type of $\operatorname{PrP}^{\mathrm{Sc}}$, J. Neuropathol. Exp. Neurol. (2005) 64:902-909.

[100] Rachidi W., Mangé A., Senator A., Guiraud P., Riondel J., Benboubetra M., et al., Prion infection impairs copper binding of cultured cells, J. Biol. Chem. (2003) 278:14595-14598.

[101] Rachidi W., Vilette D., Guiraud P., Arlotto M., Riondel J., Laude H., et al., Expression of Prion Protein Increases Cellular Copper Binding and Antioxidant Enzyme Activities but Not Copper Delivery, J. Biol. Chem. (2003) 278:9064-9072.

[102] Rambold A.S., Miesbauer M., Rapaport D., Bartke T., Baier M., Winklhofer K.F., Tatzelt J., Association of $\mathrm{Bcl}-2$ with misfolded prion protein is linked to the toxic potential of cytosolic PrP, Mol. Biol. Cell (2006) 17:3356-3368.

[103] Rogers M., Yehiely F., Scott M., Prusiner S.B., Conversion of truncated and elongated prion proteins into the scrapie isoform in cultured cells, Proc. Natl. Acad. Sci. U.S.A. (1993) 90:3182-3186.

[104] Roucou X., Giannopoulos P.N., Zhang Y., Jodoin J., Goodyer C.G., LeBlanc A., Cellular prion protein inhibits proapoptotic Bax conformational change in human neurons and in breast carcinoma MCF-7 cells, Cell Death Differ. (2005) 12:783-795.

[105] Roucou X., LeBlanc A.C., Cellular prion protein neuroprotective function: implications in prion diseases, J. Mol. Med. (2005) 83:3-11.

[106] Rubinsztein D.C., DiFiglia M., Heintz N., Nixon R.A., Qin Z.H., Ravikumar B., et al., Autophagy and its possible roles in nervous system diseases, damage and repair, Autophagy (2005) 1:11-22.

[107] Russelakis-Carneiro M., Hetz C., Maundrell K., Soto C., Prion replication alters the distribution of synaptophysin and caveolin 1 in neuronal lipid rafts, Am. J. Pathol. (2004) 165:1839-1848.

[108] Sáez-Valero J., Angeretti N., Forloni G., Caspase-3 activation by beta-amyloid and prion protein peptides is independent from their neurotoxic effect, Neurosci. Lett. (2000) 293:207-210.

[109] Santuccione A., Sytnyk V., Leshchyns'ka I., Schachner M., Prion protein recruits its neuronal receptor NCAM to lipid rafts to activate p59fyn and to enhance neurite outgrowth, J. Cell Biol. (2005) 169:341-354.

[110] Schätzl H.M., Laszlo L., Holtzman D.M., Tatzelt J., DeArmond S.J., Weiner R.I., et al., A hypothalamic neuronal cell line persistently infected with scrapie prions exhibits apoptosis, J. Virol. (1997) 71:8821-8831.

[111] Schneider B., Mutel V., Pietri M., Ermonval M., Mouillet-Richard S., Kellermann O., NADPH oxidase and extracellular regulated kinases $1 / 2$ are targets of prion protein signaling in neuronal and nonneuronal cells, Proc. Natl. Acad. Sci. USA (2003) 100:1332613331.

[112] Sikorska B., Mechanisms of neuronal death in transmissible spongiform encephalopathies, Folia Neuropathol. (2004) 42 Suppl B:89-95. 
[113] Silveira J.R., Raymond G.J., Hughson A.G., Race R.E., Sim V.L., Hayes S.F., Caughey B., The most infectious prion protein particles, Nature (2005) 437:257-261

[114] Sisó S., Puig B., Varea R., Vidal E., Acín C., Prinz M., et al., Abnormal synaptic protein expression and cell death in murine scrapie, Acta Neuropathol. (2002) 103:615-626.

[115] Solforosi L., Criado J.R., McGavern D.B., Wirz S., Sánchez-Alavez M., Sugama S., et al., Crosslinking cellular prion protein triggers neuronal apoptosis in vivo, Science (2004) 303:1514-1516.

[116] Sponne I., Fifre A., Koziel V., Kriem B., Oster T., Olivier J.L., Pillot T., Oligodendrocytes are susceptible to apoptotic cell death induced by prion proteinderived peptides, Glia (2004) 47:1-8.

[117] Stewart L.R., White A.R., Jobling M.F., Needham B.E., Maher F., Thyer J., et al., Involvement of the 5-lipoxygenase pathway in the neurotoxicity of the prion peptide PrP106-126, J. Neurosci. Res. (2001) 65:565-572.

[118] Stewart R.S., Harris D.A., A transmembrane form of the prion protein is localized in the Golgi apparatus of neurons, J. Biol. Chem. (2005) 280:1585515864.
[119] Thellung S., Villa V., Corsaro A., Arena S., Millo E., Damonte G., et al., p38 MAP kinase mediates the cell death induced by PrP106-126 in the SH-SY5Y neuroblastoma cells, Neurobiol. Dis. (2002) 9:69-81.

[120] Thellung S., Villa V., Corsaro A., Pellistri F., Venezia V., Russo C., et al., ERK1/2 and p38 MAP kinases control prion protein fragment 90-231-induced astrocyte proliferation and microglia activation, Glia (2007) 55:1469-1485.

[121] Unterberger U., Höftberger R., Gelpi E., Flicker H., Budka H., Voigtländer T., Endoplasmic reticulum stress features are prominent in Alzheimer disease but not in prion diseases in vivo, J. Neuropathol. Exp. Neurol. (2006) 65:348-357.

[122] Vilette D., Cell models of prion infection, Vet. Res. (2007) 39:10.

[123] Vincent I., Pae C.I., Hallows J.L., The cell cycle and human neurodegenerative disease, Prog Cell Cycle Res (2003) 5:31-41.

[124] Weissmann C., The state of the prion, Nat. Rev. Microbiol. (2004) 2:861-871.

[125] Yedidia Y., Horonchik L., Tzaban S., Yanai A., Taraboulos A., Proteasomes and ubiquitin are involved in the turnover of the wild-type prion protein, EMBO J. (2001) 20:5383-5391. 